\title{
Evaluation of Maxillary Sinus Width and Lateral Wall Thickness Using Cone- Beam Computed Tomography
} Konik Işınlı Bilgisayarlı Tomografi ile Maksiller Sinüs Geniş̧liği ve
Lateral Duvar Kalınlığının Değerlendirilmesi

(D) Nazan Kocak Topbas ${ }^{1}$, (1) Esin Alpoz ${ }^{2}$

${ }^{1}$ Mersin University Faculty of Dentistry, Department of Oral and Maxillofacial Radiology, Mersin, Turkey

${ }^{2}$ Ege University Faculty of Dentistry, Department of Oral and Maxillofacial Radiology, İmir, Turkey

Keywords

Cone-beam computed tomography, classification, maxillary sinus, sinus floor augmentation

\section{Anahtar Kelimeler}

Konik ışınlı bilgisayarlı tomografi, sınıflandırma, maksiller sinüs, sinüs tabanı ogmentasyonu

Received/Geliş Tarihi : 06.07.2020

Accepted/Kabul Tarihi : 13.12.2020

doi:10.4274/meandros.galenos.2020.49140

Address for Correspondence/Yazışma Adresi: Nazan Kocak Topbas MD,

Mersin University Faculty Dentistry, Department of Oral and Maxillofacial Radiology, Mersin, Turkey

Phone : +90 5458297898

E-mail : nazannkocak@gmail.com

ORCID ID: orcid.org/0000-0002-3717-2098

(C) Meandros Medical and Dental Journal, Published by Galenos Publishing House.

This is article distributed under the terms of the Creative Commons Attribution NonCommercial 4.0 International Licence (CC BY-NC 4.0).

\begin{abstract}
Objective: This study aimed to measure the lateral wall thickness (LWT) and width of the maxillary sinus using cone-beam computed tomography (CBCT) to prevent intra- and post-operative complications by formulating a new sinus classification. Materials and Methods: Residual ridge height, maxillary sinus width (SW) and lateral wall thickness (LWT) were measured by analysing CBCT scans from 246 edentulous sites. The SW and LWT were measured at $3 \mathrm{~mm}$ and $5 \mathrm{~mm}$, respectively, from the sinus floor. The mean SW was stratified by the residual ridge height $(<4 ; \leq 4$ and $<7$; $\leq 7$ and $<10 ; \geq 10 \mathrm{~mm}$ ), study site and measurement level.

Results: The mean SW increased at molar sites and at sites with lower residual ridge heights. Sinuses were categorised based on the $33^{\text {rd }}$ and $67^{\text {th }}$ percentile $S W$ values at $3 \mathrm{~mm}$ and $5 \mathrm{~mm}$, respectively. The mean value at the lower boundary was $9.33(1.85)$ $\mathrm{mm}$, with the $33^{\text {rd }}$ and $67^{\text {th }}$ percentiles being 8.62 and $10.11 \mathrm{~mm}$, and the mean value at the upper boundary was $11.72(2.20) \mathrm{mm}$, with the same percentiles being 10.81 and $12.59 \mathrm{~mm}$, respectively. The mean LWTs at 3 and $5 \mathrm{~mm}$ were 1.67 and $1.56 \mathrm{~mm}$, respectively.

Conclusion: The proposed SW classification and LWT may help predict the difficulty of sinus elevation when selecting appropriate surgical approaches.
\end{abstract}

Öz

Amaç: Bu çalışmanın amacı, ameliyat sırasında ve sonrası komplikasyonları önlemek amacıyla yeni bir sinüs sınıflandırması formüle ederek, konik ışınlı bilgisayarlı tomografi yardımıyla lateral duvar kalınlığını ve maksiller sinüs genişliğini ölçmektir. Gereç ve Yöntemler: İki yüz kırk altı dişsiz bölgeden alınan konik ışınlı bilgisayarlı tomografi taramaları analiz edilerek, rezidüel sırt yüksekliği, maksiller sinüs genişliği ve lateral duvar kalınlığı ölçüldü. Sinüs genişliği ve lateral duvar kalınlığı sinüs tabanından 3 ve $5 \mathrm{~mm}$ mesafelerde ölçüldü. Ortalama sinüs genişliği rezidüel sırt yüksekliği $(<4 ; \leq 4$ ve $<7 ; \leq 7$ ve $<10 ; \geq 10$ $\mathrm{mm})$, çalışma bölgesi ve tabandan ölçüm mesafelerine göre sınıflandırıldı. Bulgular: Ortalama sinüs genişliği molar bölgelerde ve daha düşük rezidüel sırt yüksekliğine sahip bölgelerde arttı. Sinüsler 3 ve $5 \mathrm{~mm}$ 'de 33 . ve 67 . yüzdelik dilimlerde sinüs genişliği değerlerine göre sınıflandırıldı. Alt 
sınırdaki ortalama değer 9,33 $(1,85) \mathrm{mm}$, 33. ve 67. persentiller 8,62 ve $10,11 \mathrm{~mm}$ ve üst sınırdaki $11,72(2,20) \mathrm{mm}$, aynı yüzdelikler sırasıyla 10,81 ve $12,59 \mathrm{~mm}$ idi. Ortalama lateral duvar kalınlığı 3 ve $5 \mathrm{~mm}$ 'de sırasıyla 1,67 ve 1,56 mm idi. Sonuç: Önerilen sinüs genişliği sınıflandırması ve lateral duvar kalınlığı, uygun cerrahi yaklaşımları seçerken sinüs elevasyonunda güçlüğün tahmin edilmesine yardımcı olabilir.

\section{Introduction}

Tooth extractions, resorptions and progressive pneumatization of maxillary sinuses can complicate dental implant placement in the posterior maxillary edentulous region (1-3). The anatomical structures of maxillary sinuses limit surgical procedures. Factors such as maxillary sinus width (SW) (distance between the medial and lateral sinus wall), sinus lateral wall thickness (LWT) and residual ridge height (RRH) influences surgical success. These measurements determine implant placement, orientation and size. Therefore, surgical procedures to increase vertical $\mathrm{RRH}$ via sinus lifting have been developed.

The two sinus augmentation methods are crestal osteotomy (crestal sinus lift or closed sinus lift) and lateral window approaches. The latter, which protects the sinus membrane is preferred when residual bone height is particularly poor. Maxillary sinus floor elevation is associated with high implant survival rates, but it carries the risk of complications. Damage to the sinus membrane during sinus lift procedures is the most common issue, but complications may also develop post-operatively (4-7). Therefore, reducing membrane tension from the medial wall during the lift surgery is quite effective in decreasing perforation risk (8). In addition, in this region that is rich in blood vessels, the medial wall supplies blood support for grafting in the lateral window sinus elevation technique. The lateral walls include posterior superior alveolar artery and infraorbital arteries that supply the sinus membrane with blood (8). Therefore, it is also important to position the lateral window perfectly during the lift surgery.

The maxillary sinus mediolateral dimension being too small or large for sinus lift procedures may increase membrane perforation risks. In addition to the angulation between the medial and lateral walls of the sinus, the distance between these walls is also effective in the mediolateral dimension of the maxillary sinus and has an important role in augmentation by osteotomy. In the narrow SWs, contact between implants and sinus walls maximizes.
Thus, this situation promotes vascular blood supply for bone formation. However, there is an increased risk of perforation in the narrow sinus compared to wider cases $(8,9)$. Therefore, narrow sinuses and sharp wall angles are related and are associated with increased membrane perforation (10).

In addition to the angle and distance between the lateral and medial walls, LWT is another technical and anatomical factor involved in membrane perforation (11-13). This also means that LWT must be considered during surgery to prevent possible membrane perforation (14). Correct diagnosis of maxillary sinus anatomy can prevent many complications, making it important to perform a sufficient pre-surgical study of the area using advanced imaging techniques, such as cone beam computed tomography (CBCT).

Previous studies have investigated the anatomy of maxillary sinuses via computed tomography (CT) or panoramic X-rays (2D) (15), but there is no wellrounded study evaluating maxillary SW and LWT using СВCT. Therefore, the objectives of this study are as follows:

1. To measure SW and LWT, at different heights from the sinus floor at edentulous sites on CBCT scans.

2. To propose a new sinus classification based on SW values and evaluate their clinical implications for augmentations.

3. To investigate the influence of age and sex on the dimensions of LWT, SW and RRH.

\section{Materials and Methods}

This study was approved by the Ethics Committee for Clinical Research at Ege University Faculty of Medicine (decision no: 14-7.1/6, date: 08.09.2014), and signed informed consent form was receipted by the participants.

\section{Study Sample}

We evaluated CBCT scans of 400 patients who visited the University Faculty of Dentistry for placement of dental implants between 2015 and 2020 . CBCT scanning was performed to evaluate implant placements. Patients' demographic findings, number of teeth lost and medical histories were recorded. 


\section{Image Acquisition}

CBCT images were obtained using a Kodak 9000 3D (Kodak Dental Systems, Carestream, Rochester, NY, USA) with a $5 \times 3.7 \mathrm{~cm}$ field of view (FOV), $70 \mathrm{kVp}$, $10 \mathrm{~mA}$, a scanning time of $24 \mathrm{~s}$, a voxel size of 0.076 $\mathrm{mm}$ and a slice thickness of $0.076 \mathrm{~mm}$. The scans in this study were selected from archives of University Faculty of Dentistry Department of Oral and Maxilofacial Radiology CBCT database. CBCT images were reviewed and measured by a single examiner (N.K.T.) using Kodak 3D Imaging Software 3.1.9 (Kodak Dental Systems, Carestream, Rochester, NY, USA). All examinations to create adequate image quality; It was carried out by an expert licensed radiologist with the required minimum optimal exposure dose and the smallest FOV.

\section{Inclusion Criteria}

Axial, sagittal and cross-sectional images projected by a 28 -inch desktop monitor of $1024 \times 768$ pixels under normal room lighting were evaluated. Included $\mathrm{CBCT}$ images met the following criteria:

1. Presence of edentulous sites in the vicinity of the maxillary sinus.

2. Preferably one or two missing teeth so that localization could be clearly identified.

3. Presence of adjacent teeth to the edentulous area to identify locations in correspondence to the missing tooth sites.

4. Visible maxillary sinus, measurable from the floor to at least $6 \mathrm{~mm}$ in height.

Images were excluded if any of the following criteria were met:

1. The images were unclear or incomplete.

2. Edentulous sites in correspondence to any tooth sites could not be located.

3. Sinus pathology made measurement impossible.

4. The alveolar ridge outline could not be distinguished.

5. The sinus had been grafted or implants had been placed.

6. The adjacent teeth were too mesialise (mesial tipping) precluding measurements.

\section{Data Collection}

Reconstructed images were reoriented to bring the hard palate parallel with the ground and may be used to view certain anatomic areas from all aspects. At the sagittal section images, reference arches were drawn at the level of the crestal bone to comply with the ridge centres. Coronal section images including the centres of each missing tooth site were selected for SW, LWT and RRH measurements. On these images, data were measured using an inbuilt digital calliper, including SW, LWT and RRH at 3 and $5 \mathrm{~mm}$ from the sinus floor (Figure 1). SW, LWT and RRH measurements of the posterior maxillary region were completed at edentulous sites from the first premolar to the second molar on the 246 CBCT images (154 scans were rejected because of low quality images; evidence of previous implant placement/ augmentation procedures, leaving insufficient space to place an implant; or no adjacent teeth). SW was measured from the medial to lateral walls of the sinuses. LWT was measured from the inner to outer cortical surfaces in the lateral walls. The minimum and maximum RRH from the sinus floor to the crest top were measured. Sinus classification was performed in patients who were eligible for sinus augmentation in $\mathrm{RRH}$-maximum (max RRH in the investigated sites) $<10 \mathrm{~mm}$.

\section{Study Design}

Missing tooth sites were categorised: premolar (P), molar (M), premolars (PP), molars (MM) and premolar and molar (PM). RRH ranges of 0-3.99 mm, 4-6.99 $\mathrm{mm}, 7-9.99 \mathrm{~mm}$ and $\geq 10 \mathrm{~mm}$ at edentulous site were classified as severely deficient (SvD), moderately deficient (MdD), slightly deficient (SID), or normally

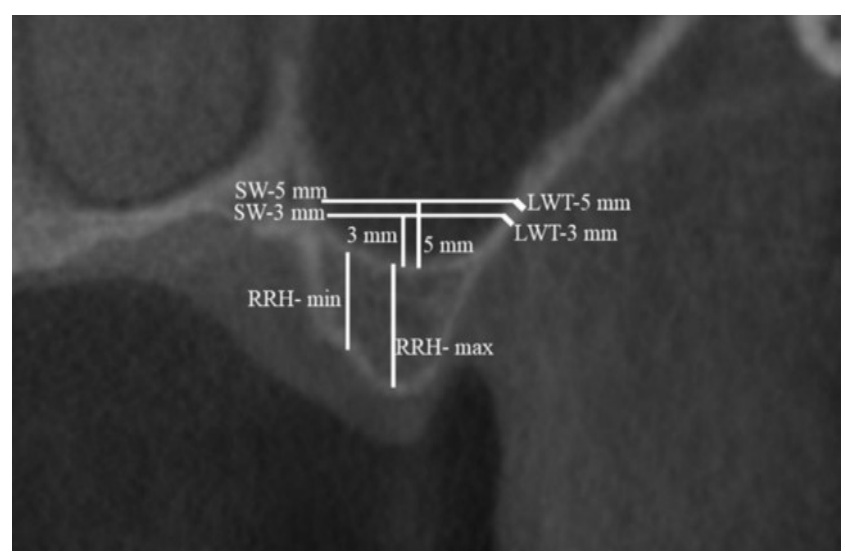

Figure 1. Demonstration of measurements of anatomical landmarks

SW-3-mm: Sinus width which was at $3 \mathrm{~mm}$ above from the sinus floor, SW-5-mm: Sinus width which was at $5 \mathrm{~mm}$ above from the sinus floor, LWT-3-mm: Lateral wall thickness which was at $3 \mathrm{~mm}$ above from the sinus floor, LWT-5-mm: Lateral wall thickness which was at 5 $\mathrm{mm}$ above from the sinus floor, RRH-max $\backslash \mathrm{min}$ : Residual ridge height maximum $\backslash$ minimum 
deficient (ND), respectively. SWs were obtained at each measurement level of each missing tooth site and are expressed as mean [standard deviation (SD)] in $\mathrm{mm}$.

\section{Statistical Analysis}

The SWs of three RRH groups $(3 \mathrm{~mm}$ and $5 \mathrm{~mm}$ for SVD, MdD, and SID) were combined to represent $\mathrm{SW}$ at the usual lower limit $(3 \mathrm{~mm})$ and upper $(5 \mathrm{~mm})$ of the lateral window osteotomy. The mean (SD), median and $33^{\text {rd }}$ and $67^{\text {th }}$ percentile values for SW at the lower and upper limits were worked out.

A One-Way ANOVA was used to compare the measurements, investigated sites and age variables. Independent sample t-tests were used to compare these measurements by gender. The intraclass correlation coefficient (ICC) was calculated to determine the level of agreement between the measurements. Relationships between the variables SW-5-mm (SW which was at $5 \mathrm{~mm}$ above from the sinus floor), LWT-5-mm (LWT which was at $5 \mathrm{~mm}$ above from the sinus floor), RRH-max and number of missing teeth were investigated via Pearson's correlation coefficient. The mean (SD), median and $33^{\text {rd }}$ and $67^{\text {th }}$ percentile values for the SW at the lower and upper limits were worked out. SPSS 25.0 (SPSS Inc., Chicago, IL, USA) was used for statistical analyses.

\section{Results}

A total of 246 scans were included for analysis. Of the 246 evaluated CBCT scans, $46.7 \%$ belonged to female patients and $53.3 \%$ to males (mean age of 49.1 years old and age range from 18 to 90 years old).

LWT-3-mm (LWT-3-mm above the sinus floor) showed no significant difference by the investigated sites ( $p>0.05)$. However, SW-3-mm (SW-3-mm above the sinus floor), SW-5-mm, LWT-5-mm, (SW and LWT-5-mm above the sinus floor) RRH-max and RRHminimum ( $\max$ and $\min \mathrm{RRH}$ in the investigated sites) values showed significant differences by the investigated sites $(p<0.05)$.

The SW-3-mm and SW-5-mm averages of PM, $M M$ and $M$ were significantly higher than those of PP and P $(p<0.05)$. The LWT-5-mm averages of PM, $P$ and $M$ were significantly higher than those of $M M$ $(p<0.05)$. The averages of RRH-max and RRH-min were significantly higher in PP and $\mathrm{P}$ than those of $\mathrm{MM}, \mathrm{PM}$ and $M(p<0.05)$.
The ICC showed strong agreement between the results of the first, second and third series of measurements $(|\mathrm{CC}|>0.75)$. Therefore, the mean values of dual measurements were applied for further analysis to minimise error in the variable measurements.

Correlations were evaluated at a single measurement level $(5 \mathrm{~mm})$ only. An insignificant negative correlation was found between SW-5-mm and LWT-5-mm. SW-5-mm was negatively correlated with both RRH-max and number of missing teeth. Finally, there was a significant positive correlation between LWT-5-mm and RRH-max and an insignificant negative correlation between LWT-5-mm and number of missing teeth (Table 1).

The mean SW is presented in Table 2, classified by $\mathrm{RRH}$, investigated site and measurement level. In RRH-max, 22, 81, 52 and 91 investigated sites were available, respectively, for SvD, MdD, SID and ND. In RRH-min, 89, 68, 37 and 52 investigated sites were available for SvD, MdD, SID and ND. In RRH-max, for the $3 \mathrm{~mm}$ measurement level of each RRH group, the mean SWs were $8.22( \pm 2.25), 9.44( \pm 1.62), 9.62$ $( \pm 1.86)$ and $7.36( \pm 2.93) \mathrm{mm}$, respectively, for SvD, $\mathrm{MdD}, \mathrm{SID}$ and ND. For the $5 \mathrm{~mm}$ measurement level of each RRH group, the mean SWs were $10.07( \pm 2.45)$, $12.10( \pm 1.94), 11.85( \pm 2.18)$ and $9.47( \pm 3.89) \mathrm{mm}$, respectively, for SvD, MdD, SID and ND. In RRH-min, for the $3 \mathrm{~mm}$ measurement level of each RRH group, the mean SWs were $9.02(1.70), 9.47( \pm 2.28), 9.07$ $( \pm 2.39)$ and $6.24( \pm 2.67) \mathrm{mm}$, respectively, for SvD, $\mathrm{MdD}, \mathrm{SID}$ and ND. For the $5 \mathrm{~mm}$ measurement level of each RRH group, the mean SWs were $11.41( \pm 2.02)$, $11.87( \pm 2.69), 10.96( \pm 3.37)$ and $8.48( \pm 3.94) \mathrm{mm}$, respectively, for SvD, MdD, SID and ND (Table 2).

When RRH-max and RRH-min were evaluated for sinus augmentation requirements, SvD, MdD and SID were further analysed for SW classifications. The distributions of SW at the lower and upper limits of the lateral window osteotomy were examined. On the basis of the $33^{\text {rd }}$ and $67^{\text {th }}$ percentile SW values, a new sinus classification was proposed (Table 3 ). The mean value at the lower limit was $9.33( \pm 1.85)$, with the $33^{\text {rd }}$ and $67^{\text {th }}$ percentiles at 8.62 and 10.11 $\mathrm{mm}$, respectively. The mean value at the upper limit of the lateral window osteotomy was $11.72( \pm 2.20)$, with the $33^{\text {rd }}$ and $67^{\text {th }}$ percentiles at 10.81 and 12.59 $\mathrm{mm}$, respectively (Table 3 ). The distributions of SW 


\begin{tabular}{|c|c|c|c|c|c|}
\hline Measurements & Statistical analysis methods & SW-5-mm & LWT-5-mm & RRH-max & $\begin{array}{l}\text { Number of } \\
\text { missing teeth }\end{array}$ \\
\hline \multirow{2}{*}{ SW-5-mm } & Pearson correlation & 1 & - & - & - \\
\hline & Significance (two-tailed) & - & - & - & - \\
\hline \multirow{2}{*}{ LWT-5-mm } & Pearson correlation & -0.084 & 1 & - & - \\
\hline & Significance (two-tailed) & 0.196 & - & - & - \\
\hline \multirow{2}{*}{ RRH-max } & Pearson correlation & $-0.399 * *$ & $0.372 * *$ & 1 & - \\
\hline & Significance (two-tailed) & 0.000 & 0.000 & - & - \\
\hline \multirow{2}{*}{ Number of missing teeth } & Pearson correlation & $0-.146^{*}$ & -0.079 & $0.172 * *$ & 1 \\
\hline & Significance (two-tailed) & 0.024 & 0.223 & 0.007 & - \\
\hline
\end{tabular}

at the lower and upper limits of the lateral window osteotomy are plotted in Figures $2 \mathrm{a}$ and $\mathrm{b}$. A sinus classification was proposed based on the $33^{\text {rd }}$ and $67^{\text {th }}$ percentile SW values. For narrow, average and wide sinuses, the SWs at the lower limit of lateral windows were $<8.62,8.62-10.11$ and $>10.11 \mathrm{~mm}$; at the upper limit, the SWs were $<10.81,10.81-12.59$ and $>12.59$

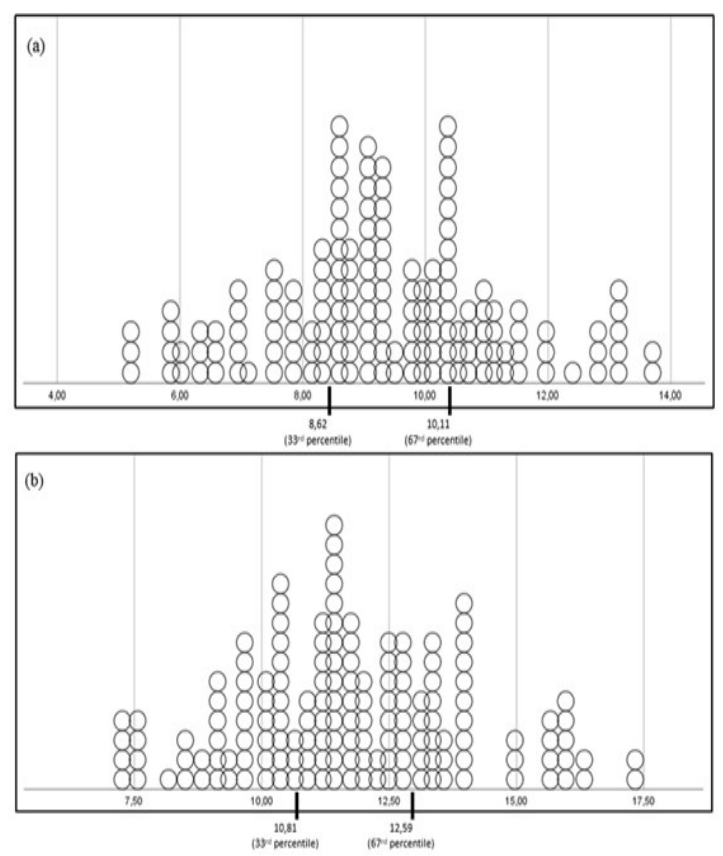

Figure 2. Distributions of sinus width measurements from 155 sites with thirty-third and sixty-seventh percentile values at the (a) lower limit and (b) upper limit of lateral window osteotomy $\mathrm{mm}$, respectively (Table 4). It was found that the widest and narrowest sinuses were respectively on the MdD and SvD groups, at both measurement level and RRH groups (Table 3 ).

When measurements were compared by gender, the SW-3-mm and RRH-max mean value were not statistically significant $(p>0.05)$. However, the SW5-mm, LWT-3-mm and LWT-5-mm averages were significantly different in favour of male partially edentulous patients; RRH-min averages were significantly different in favour of female partially edentulous patiens $(p<0.05)$ (Table 5$)$. When the measurements were compared by age, SW-3-mm, sW-5-mm, LWT-3-mm, LWT-5-mm, RRH-min and RRHmax averages were not statistically different $(p>0.05)$ (Table 6).

\section{Discussion}

Sinus membrane elevation via lateral windows creates complications due to sinus-associated fragile structures and anatomical variations. One such complication is Schneiderian membrane perforation, the most common intraoperative complication during sinus elevation. Also, membrane perforation may consist as a result of difficulties in approaching the surgical site, indirect and/or blind manipulation a lateral window instrument-related complications during elevation and the thin structure of the membrane itself (7). 


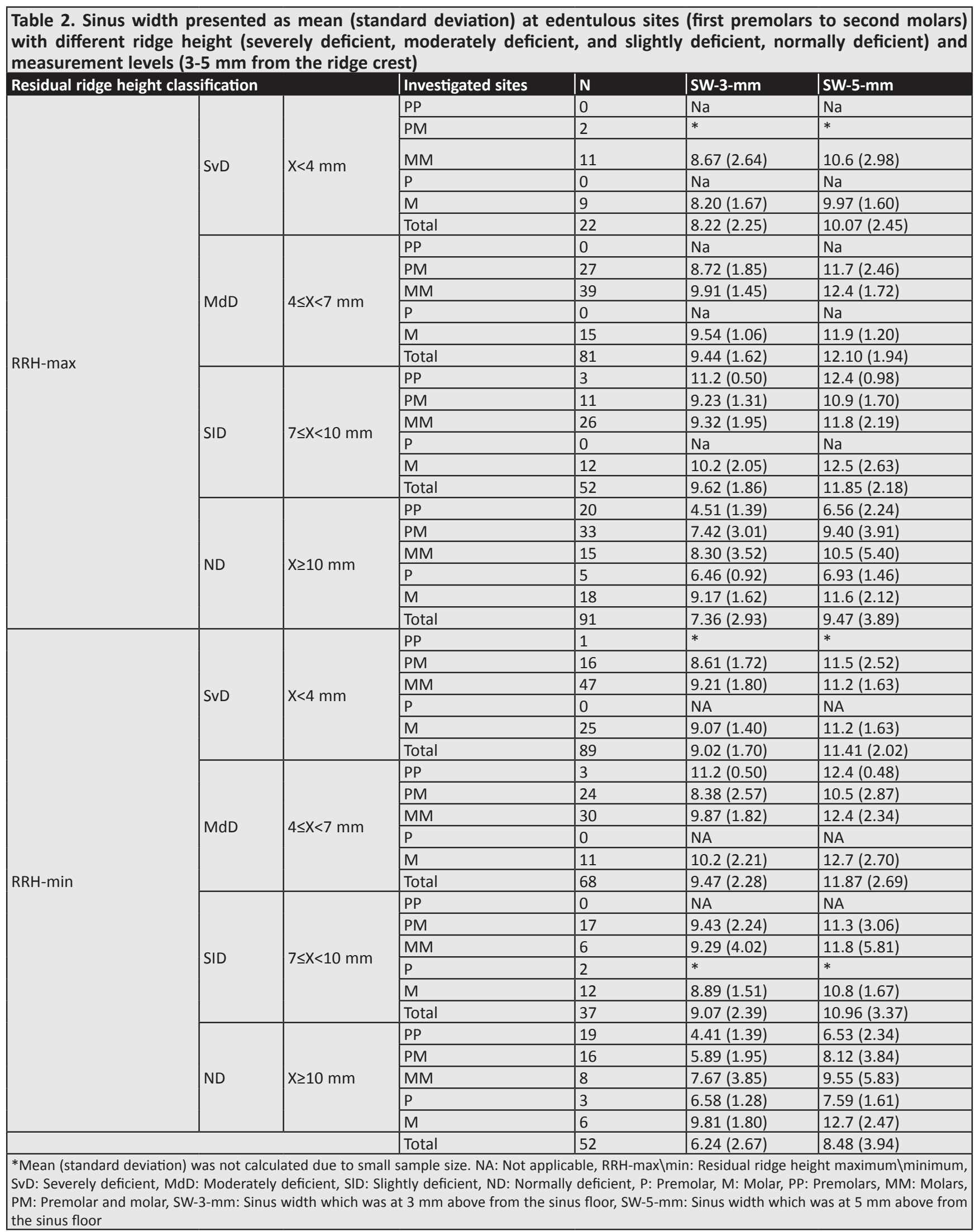




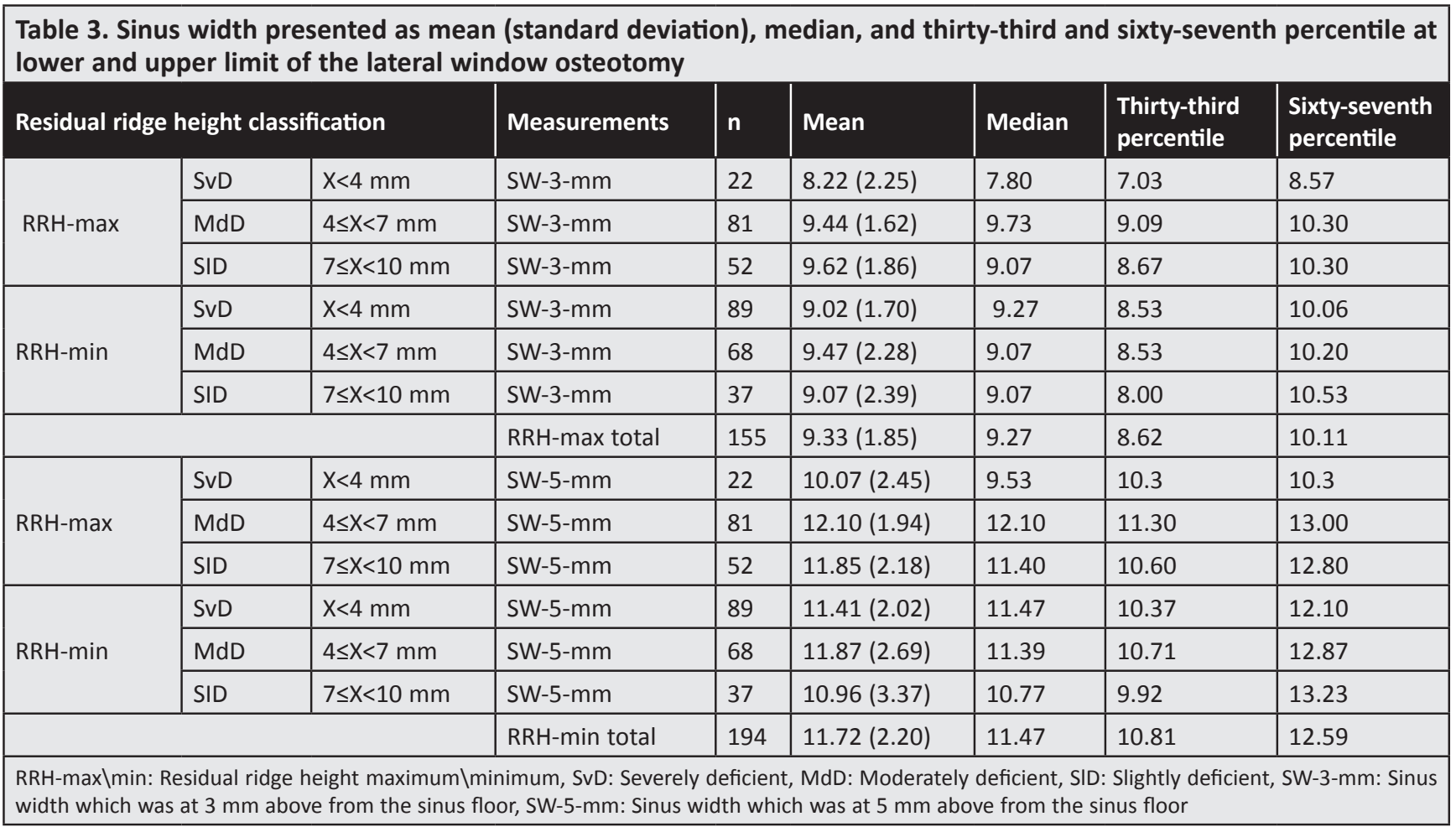

Table 4. New sinus classification based on sinus width at the lower and upper limit of lateral window osteotomy

\begin{tabular}{|l|l|l|l|}
\hline Sinus width $(\mathbf{m m})$ & Narrow & Average & Wide \\
\hline SW-3-mm & $<8.62$ & $8.62-10.11$ & $10.11>$ \\
\hline SW-5-mm & $<10.81$ & $10.81-12.59$ & $12.59>$ \\
\hline \multicolumn{2}{|l}{ SW-3-mm: Sinus width which was at 3 mm above from the sinus floor, SW-5-mm: Sinus width which was at 5 mm above from the sinus floor } \\
\hline
\end{tabular}

Table 5. Comparison of measurements by gender

\begin{tabular}{|c|c|c|c|c|c|}
\hline Measurements & Gender & $\mathbf{N}$ & Mean & Standard deviation & Sig. \\
\hline \multirow{2}{*}{ sW-3-mm } & Female & 115 & 8.31 & 2.79 & \multirow{2}{*}{0.06} \\
\hline & Male & 131 & 8.91 & 2.12 & \\
\hline \multirow{2}{*}{ SW-5-mm } & Female & 115 & 10.42 & 3.38 & \multirow{2}{*}{0.02} \\
\hline & Male & 131 & 11.39 & 2.74 & \\
\hline \multirow{2}{*}{ LWT-3-mm } & Female & 115 & 1.46 & 0.70 & \multirow{2}{*}{0.00} \\
\hline & Male & 131 & 1.91 & 1.08 & \\
\hline \multirow{2}{*}{ LWT-5-mm } & Female & 115 & 1.41 & 0.69 & \multirow{2}{*}{0.01} \\
\hline & Male & 131 & 1.69 & 0.92 & \\
\hline \multirow{2}{*}{ RRH-min } & Female & 115 & 7.73 & 5.86 & \multirow{2}{*}{0.01} \\
\hline & Male & 131 & 6.00 & 4.50 & \\
\hline \multirow{2}{*}{ RRH-max } & Female & 115 & 10.24 & 5.73 & \multirow{2}{*}{0.06} \\
\hline & Male & 131 & 8.96 & 5.02 & \\
\hline
\end{tabular}

SW-3-mm: Sinus width which was at $3 \mathrm{~mm}$ above from the sinus floor, SW-5-mm: Sinus width which was at $5 \mathrm{~mm}$ above from the sinus floor, LWT-3$\mathrm{mm}$ : Lateral wall thickness which was at $3 \mathrm{~mm}$ above from the sinus floor), LWT-5-mm: Lateral wall thickness which was at $5 \mathrm{~mm}$ above from the sinus floor), RRH-max\min: Residual ridge height maximum\minimum 


\begin{tabular}{|c|c|c|c|c|c|}
\hline Measurements & Age & n & Mean & SD & Sig. \\
\hline \multirow{3}{*}{ SW-3-mm } & $18-35$ & 27 & 9.08 & 2.23 & \multirow{3}{*}{0.18} \\
\hline & $36-53$ & 127 & 8.82 & 2.44 & \\
\hline & 54-71 & 91 & 8.28 & 2.48 & \\
\hline \multirow{3}{*}{ SW-5-mm } & $18-35$ & 27 & 11.22 & 2.62 & \multirow{3}{*}{0.13} \\
\hline & 36-53 & 127 & 11.30 & 2.89 & \\
\hline & 54-71 & 91 & 10.41 & 3.34 & \\
\hline \multirow{3}{*}{ LWT-3-mm } & $18-35$ & 27 & 1.84 & 0.78 & \multirow{3}{*}{0.33} \\
\hline & $36-53$ & 127 & 1.71 & 1.12 & \\
\hline & 54-71 & 91 & 1.61 & 0.68 & \\
\hline \multirow{3}{*}{ LWT-5-mm } & $18-35$ & 27 & 1.92 & 1.13 & \multirow{3}{*}{0.14} \\
\hline & 36-53 & 127 & 1.54 & 0.90 & \\
\hline & $54-71$ & 91 & 1.47 & 0.56 & \\
\hline \multirow{3}{*}{ RRH-min } & $18-35$ & 27 & 5.98 & 5.08 & \multirow{3}{*}{0.47} \\
\hline & 36-53 & 127 & 6.61 & 5.27 & \\
\hline & $54-71$ & 91 & 7.24 & 5.21 & \\
\hline \multirow{3}{*}{ RRH-max } & $18-35$ & 27 & 8.13 & 5.58 & \multirow{3}{*}{0.36} \\
\hline & $36-53$ & 127 & 9.55 & 5.40 & \\
\hline & 54-71 & 91 & 9.88 & 5.27 & \\
\hline \multicolumn{6}{|c|}{$\begin{array}{l}\text { *The 72+ age group is not included in the analysis due to small sample size, SW-3-mm: Sinus width which was at } 3 \mathrm{~mm} \text { above from the sinus floor, } \\
\text { SW-5-mm: Sinus width which was at } 5 \mathrm{~mm} \text { above from the sinus floor, LWT-3-mm: Lateral wall thickness which was at } 3 \mathrm{~mm} \text { above from the sinus } \\
\text { floor, LWT-5-mm: Lateral wall thickness which was at } 5 \mathrm{~mm} \text { above from the sinus floor, RRH-max } \backslash \text { min: Residual ridge height maximum Iminimum, SD: } \\
\text { Standard deviation }\end{array}$} \\
\hline
\end{tabular}

In addition to, the presence of an overly large or narrow sinus, such as a thin or thick lateral wall, increases the risk of membrane perforation $(16,17)$. However, despite this, few clinical studies $(8,18$ 22 ) have assessed the LWT of maxillary sinuses, the width of the mediolateral sinus or their relationship to various parameters. This study evaluates LWT and SW in patients with one and two edentulous sites using CBCT with a limited FOV. It proposes a new sinus classification based on those values to outline clinical implications for augmentation. It investigates the influence of age and sex on bony structures surrounding the sinus and determines the mean value of each parameter for the evaluated sample. To the best of our knowledge, this study is the most comprehensive examination of radiological markers of lateral wall osteotomy available.

Zijdervald et al. (16) found that LWT to be mostly thin (78\%), in their study. Because lateral wall evaluation was performed intraoperatively, the lateral wall was defined as thin if the mucocilium was greyish- bluish and thick if the lateral wall was at least as thick as the diameter of a stainless steel bur $(2.3 \mathrm{~mm})(16)$. Similar to this study, the thicknesses obtained at each investigated site were found to be smaller than $2.3 \mathrm{~mm}$. Therefore, it is important to evaluate LWT before surgical operations, since the integrity of sinus membranes may be affected during procedures.

In lateral wall osteotomy, infracture and wall-off techniques are used $(23,24)$. The infracture technique involves tapping of the lateral wall as a roof over the graft materials, while in the wall-off technique, the lateral wall should be removed to gain an access to the sinus. In both techniques, it is recommended to place the inferior border of the window at a distance of 3-5 $\mathrm{mm}$ from the sinus floor, accordingly in the present study LWT, SW and RRH measurement points were assessed at 3 and $5 \mathrm{~mm}$ from the sinus floor $(23,25)$.

Based on our findings, the bone above the PP area has the highest LWT $(1.86 \mathrm{~mm})$, and the lowest LWT was documented in the MM area $(1.34 \mathrm{~mm})$ at both heights (Table 2). Therefore, care should be taken 
when preparing the lateral window or collecting bone in the $\mathrm{MM}$ region. Similar results were obtained by Kang et al. (20) in CBCT imaging of Korean patients. Kang et al. (20) reported that the lateral wall of the anterior region was generally thicker than the posterior regions. On the other hand, Yang et al. (21) indicated that LWT diminishes from the second molars to the first premolar regions. This LWT difference is caused by the position of adjacent anatomical structures $(22,26)$. Therefore, clinicians should consider these anatomical landmarks in the presurgical planning and during surgery.

LWT can be affected by chronic inflammatory diseases of the maxillary sinus (27). Therefore, further studies are needed to investigate the relationship between maxillary sinus pathologies and bone changes. Factors such as anatomical landmarks, differences in study populations and uneven sample distributions cause differences between studies (2022,26).

In this study, the relationship between dental deficiency and LWT has also been evaluated. Monje et al. (22) found that a correlation between longer edentulous spans and thinner lateral walls. It might be related with maxillary sinus pneumatization and bone resorption. This could not be replicated here because we used only one or two edentulous sites. However, similar to the study of Kang et al. (20), the thinnest LWT was observed in the MM sites of LWT-3-mm and $-5 \mathrm{~mm}$ regions (Table 2 ).

Few studies have assessed the effects of age and sex on LWT (20-22). Kang et al. (20) found a significant difference between males and females at $3 \mathrm{~mm}$ from the sinus floor. Similarly, this study demonstrated a significant difference in mean LWT between males and females at both heights $(p<0.05)$. Men were found to have thicker lateral walls than women. Important sex-specific differences are already known to occur in bone physiology, geometry and bone gonadal hormone response. Therefore, these values were significantly different between both sex $(p<0.05)$.

When RRH and SW parameters were evaluated in relation to sex in this study, SW-5-mm averages were found to be significant in favour of male partially edentulous patients, while $\mathrm{RRH}$-min averages were significant in favour of female partially edentulous patients. However, since the relation of these parameters with sex is not evaluated in the literature, comparison is not possible.
Regarding aging, it is thought that age-related pneumatization of maxillary sinuses may lead to lateral bone thinness (28). As a result, older patients may have thinner lateral sinus walls due to osteoporosis. However, in this study, LWT did not differentiate with age $(p>0.05)$. Furthermore, SW and RRH averages were not statistically different according to age ( $p>0.05)$.

Interwall angle and mediolateral wall distances from sinus morphology parameters are effective in predicting sinus membrane perforation risks in surgical procedures (8). According to Chan et al. (8) the mediolateral wall distances to reach the medial wall have been considered clinically important because they directly determine the amount of membrane elevation. Therefore, SW measurements were made from lateral osteotomy levels $(3-5 \mathrm{~mm})$ at different distances from the sinus floor in this study. Only a limited number of studies have evaluated the maxillary SW $(18,19)$. Jang et al. (19) found mean mediolateral distances at $12.7 \pm 4.0,15.2 \pm 3.7$ and $14.4 \pm 4.0$ at the second premolar, first molar and second molar, respectively, when measured from the CBCT sections of the implants. Avila et al. (18) found SWs of $10.2 \pm 3.4,12.7 \pm 3.2$ and $14.6 \pm 3.2$ at $8 \mathrm{~mm}, 10$ $\mathrm{mm}$ and $12 \mathrm{~mm}$ from the alveolar crest, respectively. However, a direct comparison with this study is not possible because different measurement levels and tooth sites were used. When collecting the data from sites with different RRHs in this study, the average SWs at $3 \mathrm{~mm}$ and $5 \mathrm{~mm}(23,25)$ for PP, PM, MM, P and $M$ sites. They were $5.64 \mathrm{~mm}, 8.13 \mathrm{~mm}, 9.34 \mathrm{~mm}, 6.46$ $\mathrm{mm}$ and $9.35 \mathrm{~mm}$ at $3 \mathrm{~mm}$ height level, respectively. They were $7.67 \mathrm{~mm}, 10.44 \mathrm{~mm}, 11.74 \mathrm{~mm}, 6.93 \mathrm{~mm}$ and 11.65 , at $5 \mathrm{~mm}$ height level respectively (Table 2).

Different classifications related to maxillary sinuses have been made, $(1,8,9,29-31)$ focusing on the adjacent structures of maxillary sinuses $(1,29-$ 31). Similar to this study, Chan et al. (8) and Teng et al. (9) evaluated mediolateral dimensions of maxillary sinuses from different heights to establish classifications of narrow, average and wide. A narrow sinus may cause the trapdoor to obstruct during the lateral sinus floor elevation procedure when creating the final horizontal position of the new floor $(3,25)$. On the other hand, narrow sinus walls, which usually complicate traditional lateral sinus floor elevation, may provide significant advantages to sinus elevation 
via crestal osteotomy (9). In this case, the presence of narrow SWs maximizes the contact of the implant to the bone along the lateral walls and prevents the use of excess grafts, providing better retention for the primary stability of the implants. This close relationship between bone and implant induces initial bone formation with abundant blood flow. In the presence of a wide sinus, it takes more time to release the Schneiderian membrane during the lateral wall sinus elevation. In this case, the crestal approach should be preferred. Tighter contact with the sinus walls can ensure a better blood supply and passage of the inductive element for ossification of the graft materials. Therefore, primary stability and predictable success will likely increase.

Chan et al. (8) and Teng et al. (9) found that SW was wider in molar sites and that RRH was smaller in these sites than in others. Their studies had higher measurements than this study, although similar results were obtained. Jang et al. (19) measured SW in the cross-sectional imaging of $\mathrm{CBCT}$, showing the apex of the implant after operation. They found that the $0 \%, 29.9 \%, 95.7 \%$ and $100 \%$ of grafts made contact with the medial walls when SW was $\geq 16.0,>12.1$, $\leq 12.1$ and $\leq 11.3 \mathrm{~mm}$, respectively. Consequently, they suggested that graft contact with the medial sinus wall tends to increase in narrower maxillary sinuses. Similarly, Zheng et al. (32) indicated that SW was $13.68 \pm 2.66 \mathrm{~mm}$ and found a positive relationship between SW and graft resorption.

When Teng et al. (9) evaluated the relationship between RRH and SW parameters, they found a significant negative correlation. Similarly, in this study, a statistically significant negative correlation was found between SW-5-mm and RRH-max. Additionally, there was a significant negative correlation between the number of missing teeth and SW-5-mm and a significant positive correlation between LWT-5-mm and RRH-max.

SW classification, which was made via small-FOV $\mathrm{CBCT}$, will help identify the sizes of maxillary sinuses and will improve predictions and success in surgical procedures. Further studies should be planned to check the performance the validity and reliability of the current classifications and to investigate their clinical inferences, which may include evaluation of various parameters such as ease of sinus elevation procedures, calculation of graft quantity, rates of complication and success of bone graft material in different SWs.

There are some limitations in our study that include a considerably less datasets for investigated premolar sites ( $P$ ), unequal ratio among the sexes (female/ male $=115 / 131$ ) and unknown times when subjects became edentulous. In this study, the proportions of $\mathrm{PP}, \mathrm{PM}, \mathrm{MM}, \mathrm{P}$ and $\mathrm{M}$ in the samples were $9 \%, 30 \%$, $37 \%, 2 \%$ and $22 \%$ respectively. Less data sample was expected for the premolars area, because molars were the most frequently lost teeth (33-37). Moreover, RRH in premolar regions is usually sufficient without sinus augmentation. The mean RRH in the sites associated with premolars (P, PP, PM) was more than $10 \mathrm{~mm}$.

\section{Conclusion}

The SW was evaluated on CBCT scans at several ranges from the ridge crest in 246 edentulous sites. Mean SW increased at molar sites and at the regions with lower RRHs. Sinuses were categorised based on $33^{\text {rd }}$ and $67^{\text {th }}$ percentile $S W$ values at 3 and $5 \mathrm{~mm}$. The mean value of the lower limit was $9.33(1.85) \mathrm{mm}$, with $33^{\text {rd }}$ and $67^{\text {th }}$ percentiles being 8.62 and 10.11 $\mathrm{mm}$ and of the upper limit was 11.72 (2.20) mm, with same percentiles being 10.81 and $12.59 \mathrm{~mm}$, respectively. Mean LWT at 3 and $5 \mathrm{~mm}$ was 1.67 and $1.56 \mathrm{~mm}$, respectively. Based on the $33^{\text {rd }}$ and $67^{\text {th }}$ percentile SW values of this study, a new maxillary sinus classification was suggested, with narrow, medium and wide dimensions. The proposed SW classification model and LWT can make the choice of surgical approaches more predictable.

\section{Ethics}

Ethics Committee Approval: This study was approved by the Ethics Committee for Clinical Research at Ege University Faculty of Medicine (decision no: 147.1/6, date: 08.09.2014).

Informed Consent: Signed informed consent form was receipted by the participants.

Peer-review: Externally and internally peerreviwed.

\section{Authorship Contributions}

Concept: N.K.T., Design: N.K.T., Supervision: E.A., Fundings: N.K.T., Materials: N.K.T., Data Collection or Processing: N.K.T., Analysis or Interpretation: N.K.T., Literature Search: N.K.T., E.A., Writing: N.K.T., E.A., Critical Review: N.K.T., E.A. 
Conflict of Interest: The authors declare that they have no conflict of interest.

Financial Disclosure: The authors declared that this study received no financial support.

\section{References}

1. Wang HL, Katranji $A . A B C$ sinus augmentation classification. Int J Periodontics Restorative Dent 2008; 28: 383-9.

2. Baldi D, Menini M, Pera F, Ravera G, Pera P. Sinus floor elevation using osteotomes or piezoelectric surgery. Int J Oral Maxillofac Surg 2011; 40: 497-503.

3. van den Bergh JP, ten Bruggenkate CM, Disch FJ, Tuinzing DB. Anatomical aspects of sinus floor elevations. Clin Oral Implants Res 2000; 11: 256-65.

4. Block MS, Kent JN. Sinus augmentation for dental implants: the use of autogenous bone. J Oral Maxillofac Surg 1997; 55: 1281-6.

5. Misch CE. Maxillary sinus augmentation for endosteal implants: organized alternative treatment plans. Int J Oral Implantol 1987; 4: 49-58.

6. Barone A, Santini S, Sbordone L, Crespi R, Covani U. A clinical study of the outcomes and complications associated with maxillary sinus augmentation. Int J Oral Maxillofac Implants 2006; 21: 81-5.

7. Pjetursson BE, Tan WC, Zwahlen M, Lang NP. A systematic review of the success of sinus floor elevation and survival of implants inserted in combination with sinus floor elevation. J Clin Periodontol 2008; 35(Suppl 8): 216-40.

8. Chan HL, Suarez F, Monje A, Benavides E, Wang HL. Evaluation of maxillary sinus width on cone-beam computed tomography for sinus augmentation and new sinus classification based on sinus width. Clin Oral Implants Res 2014; 25: 647-52.

9. Teng $M$, Cheng $Q$, Liao J, Zhang X, Mo A, Liang X. Sinus width analysis and new classification with clinical implications for uugmentation. Clin Implant Dent Relat Res 2016; 18: 89-96.

10. Velloso GR, Vidigal GM Jr, de Freitas MM, Garcia de Brito OF, Manso MC, Groisman M. tridimensional analysis of maxillary sinus anatomy related to sinus lift procedure. Implant Dent 2006; 15: 192-6.

11. Cho SC, Wallace SS, Froum SJ, Tarnow DP. Influence of anatomy on schneiderian membrane perforations during sinus elevation surgery: three-dimensional analysis. Pract Proced Aesthet Dent 2001; 13: 160-3.

12. Ulm CW, Solar P, Krennmair G, Matejka M, Watzek G. Incidence and suggested surgical management of septa in sinus-lift procedures. Int J Oral Maxillofac Implants 1995; 10: 462-5.

13. Hernández-Alfaro F, Torradeflot MM, Marti C. Prevalence and management of schneiderian membrane perforations during sinus-lift procedures. Clin Oral Implants Res 2008; 19: 91-8.

14. Palma VC, Magro-Filho O, de Oliveria JA, Lundgren S, Salata LA, Sennerby $L$. Bone reformation and implant integration following maxillary sinus membrane elevation: an experimental study in primates. Clin Implant Dent Relat Res 2006; 8: 11-24.
15. Neugebauer J, Ritter L, Mischkowski RA, Dreiseidler T, Scherer $\mathrm{P}$, Ketterle $\mathrm{M}$, et al. Evaluation of maxillary sinus anatomy by cone-beam CT prior to sinus floor elevation. Int J Oral Maxillofac Implants 2010; 25: 258-65.

16. Zijderveld SA, van den Bergh JP, Schulten EA, ten Bruggenkate $\mathrm{CM}$. Anatomical and surgical findings and complications in 100 consecutive maxillary sinus floor elevation procedures. J Oral Maxillofac Surg 2008; 66: 1426-38.

17. Schwartz-Arad D, Herzberg R, Dolev E. The prevalence of surgical complications of the sinus graft procedure and their impact on implant survival. J Periodontol 2004; 75: 511-6.

18. Avila G, Wang HL, Galindo-Moreno P, Misch CE, Bagramian RA, Rudek I, et al. The influence of the bucco-palatal distance on sinus augmentation outcomes. J Periodontol 2010; 81: 1041-50.

19. Jang HY, Kim HC, Lee SC, Lee JY. Choice of graft material in relation to maxillary sinus width in internal sinus floor augmentation. J Oral Maxillofac Surg 2010; 68: 1859-68.

20. Kang SJ, Shin SI, Herr Y, Kwon YH, Kim GT, Chung JH. Anatomical structures in the maxillary sinus related to lateral sinus elevation: a cone beam computed tomographic analysis. Clin Oral Implants Res 2013; 24(Suppl A100): 75-81.

21. Yang SM, Park SI, Kye SB, Shin SY. Computed tomographic assessment of maxillary sinus wall thickness in edentulous patients. J Oral Rehabil 2012; 39: 421-8.

22. Monje A, Catena A, Monje F, Gonzalez-García R, GalindoMoreno $P$, Suarez $F$, et al. Maxillary sinus lateral wall thickness and morphologic patterns in the atrophic posterior maxilla. J Periodontol 2014; 85: 676-82.

23. Wallace SS, Tarnow DP, Froum SJ, Cho SC, Zadeh HH, Stoupel $J$, et al. Maxillary sinus elevation by lateral window approach: evolution of technology and technique. J Evid Based Dent Pract 2012; 12(Suppl 3): 161-71.

24. Raja SV. Management of the posterior maxilla with sinus lift: review of techniques. J Oral Maxillofac Surg 2009; 67: 1730-4.

25. Woo I, Le BT. Maxillary sinus floor elevation: review of anatomy and two techniques. Implant Dent 2004; 13: 28-32.

26. Apostolakis D, Bissoon AK. Radiographic evaluation of the superior alveolar canal: measurements of its diameter and of its position in relation to the maxillary sinus floor: a cone beam computerized tomography study. Clin Oral Implants Res 2014; 25: 553-9.

27. Kim HY, Kim MB, Dhong HJ, Jung YG, Min JY, Chung SK, et al. Changes of maxillary sinus volume and bony thickness of the paranasal sinuses in longstanding pediatric chronic rhinosinusitis. Int J Pediatr Otorhinolaryngol 2008; 72: 103-8.

28. Ulm CW, Solar P, Gsellmann B, Matejka M, Watzek G. The edentulous maxillary alveolar process in the region of the maxillary sinus--a study of physical dimension. Int J Oral Maxillofac Surg 1995; 24: 279-82.

29. Misch CE, Judy KW. Classification of partially edentulous arches for implant dentistry. Int J Oral Implantol 1987; 4: 7-13.

30. Cawood JI, Howell RA. A classification of the edentulous jaws. Int J Oral Maxillofac Surg 1988; 17: 232-6.

31. Simion M, Fontana F, Rasperini G, Maiorana C. Long-term evaluation of osseointegrated implants placed in sites 
augmented with sinus floor elevation associated with vertical ridge augmentation: a retrospective study of 38 consecutive implants with 1- to 7-year follow-up. Int J Periodontics Restorative Dent 2004; 24: 208-21.

32. Zheng X, Teng M, Zhou F, Ye J, Li G, Mo A. Influence of maxillary sinus width on transcrestal sinus augmentation outcomes: radiographic evaluation based on cone beam CT. Clin Implant Dent Relat Res 2016; 18: 292-300.

33. Hirschfeld L, Wasserman B. A long-term survey of tooth loss in 600 treated periodontal patients. J Periodontol 1978; 49: 22537.

34. McFall WT Jr. Tooth loss in 100 treated patients with periodontal disease. A long-term study. J Periodontol 1982; 53: 539-49.
35. Bertl K, Mick RB, Heimel A P, Gahleitner, Stavropoulos A, Ulm C. Variation in bucco-palatal maxillary sinus width does not permit a meaningful sinus classification. Clin Oral Implants Res 2018; 29: $1220-9$.

36. Kawakami S, Botticelli D, Nakajima Y, Sakuma S, Baba S. Anatomical analyses for maxillary sinus floor augmentation with a lateral approach: A cone beam computed tomography study. Ann Anat 2019; 226: 29-34.

37. Dursun E, Keceli HG, Dolgun A, Velasco-Torres $M$, Olculer $M$, Ghoreishi R, et al. Maxillary sinus and surrounding bone anatomy with cone beam computed tomography after multiple teeth loss: a retrospective multicenter clinical study. Implant Dent 2019; 28: 226-36. 